\title{
EQUiLIBRIUM
}

Quarterly Journal of Economics and Economic Policy

2015 VOLUME 10 ISSUE 1, March

p-ISSN 1689-765X, e-ISSN 2353-3293

www.economic-policy.pl

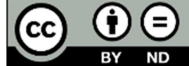

Held, B. (2015). Comparison of Public, Non-Profit and Private Hospitals. Equilibrium. Quarterly Journal of Economics and Economic Policy, 10(1), pp. 155-178, DOI: http://dx.doi.org/10.1 $\underline{\text { 2775/EQUIL.2015.008 }}$

Bärbel Held

Steinbeis-Hochschule Berlin, Germany

\section{Comparison of Public, Non-Profit and Private Hospitals}

JEL Classification: I1 10; I120; I130; P36

Keywords: analysis; comparison; health care; hospitals; soft budget constraint syndrome $(S B C)$

\begin{abstract}
The health care system in Germany is undergoing a phase of transformation. The resulting challenges and fields of action for the hospitals were described as one outcome of a scenario analysis conducted by the author. These include, for example, setting up new organisation structures, professionalising management competence or also developing a comprehensive quality management system. In the following analysis, the hospitals are to be described and compared to one another in terms of their initial conditions regarding these fields of action. The question at the focus is which different prerequisites and options the clinics have subject to their organisational structure.
\end{abstract}

\section{Introduction}

The hospital sector in Germany is undergoing a phase of transformation. The reasons are, amongst others, increasing costs, also furthered by enormous scientific advances in medical and pharmaceutical research and insufficient income, also due to the changing age structure in Germany. In addi-

(C) Copyright Institute of Economic Research \& Polish Economic Society Branch in Toruń

Date of submission: November 7, 2014; date of acceptance: February 1, 2015

* Contact: baerbel.held@shb-university.de, Steinbeis-Hochschule Berlin, Institute of Economics, 10247 Berlin, Gürtelstraße 29a/30, Germany 
tion, there are the inefficient healthcare structures, which, compared with other structures in the service provider market, remain below its potentialities. All this causes a paradigm shift of inpatient hospital care organisation in Germany.

The article builds on the already available research results by the author. Using the methodology of scenario analysis, the author has analysed the present situation of the German healthcare systems and from this has derived a trend scenario. This trend scenario describes the progressive development of regionalised, commercially oriented healthcare structures rather as a result than as a directed process, caused by the economic crisis of the public healthcare sector. According to this, not one of the fragmented participants in the healthcare system is today in a position to bring the potentials of medical top-level research, training and medical technology to the regions, to the customer, with integrated health services. The changes to the determining factors for hospitals, such as the increasing shortage of funds, the demographic change as well as the developments in medical technology and the reform course in the healthcare sector, such as the introduction of Diagnosis Related Group (DRG) payments, the repeal of the sector border between outpatient and inpatient care and the introduction of quality management and quality assurance demand consequences from the clinic operators. These include creating new organisation forms to secure financial survival, professionalising management competence, establishing a stringent management of the business processes, developing comprehensive quality management systems, adapting the portfolio to suit customer needs, professionalising the service and reflect their hospital with ethical corporate principles.

Based on this, it is to be investigated in the following, which determining factors the hospitals bring to the table, based on their formal structure, in order to rise to the challenges described in the trend scenario. Specifically the following research questions will be dealt with:

- Which initial conditions and options for action can be derived for the hospitals in the context of their formal structure?

- How does the management of the hospitals react to the options for action in the context of their formal structure?

The analysis theoretically draws upon the findings of Luhmann (1971, 1984) that system structures and/or their formal structures act as decisionmaking premises to take social action and can be used for organisational analyses. In this connection system structures are the operative programs as conditional or as purpose programs, the organisation structure as the form of coordination and communication, here in the extreme characteristic between hierarchy and market and thirdly the staff (type) and its (value) cul- 
ture. The thesis that is derived from this is that the hospitals have different possibilities for solutions and approaches to solutions to rise to the described challenges depending on their organisational structure.

In order to develop a better understanding of this thesis, public, nonprofit and private hospitals will hereafter be analysed in terms of their specific features such as program, objective target, organisation, management and leadership and governance. These specific features are to be compared to one another in the context of the challenges, fields of action and possibilities for solutions to achieve effective hospital management for the benefit of the patient.

\section{Research Methodology}

The qualitative research method in the form of qualitative, guideline-based interviews was selected as the research design.

This means that clinics of all organisation types and legal forms are included in the study. In terms of approval status, the hospitals range from maximum care to basic care. All clinics are federated in networks. Although this selection does not permit a representative statement, it does nevertheless document the trend of the respective operator and the management in the hospital. This is a conscious approach.

Alongside the case study, the analyses from the studies, an extensive literature research and also a databank research were incorporated.

Seven interviews were conducted according to the interview guideline. This method makes it possible to determine subjective views of those involved, e.g. on past events, opinions or experience, which in turn make enhanced insights possible (Bortz \& Döring, 1995, p. 283). The following persons were interviewed:

- Head of the Division Corporate Development (university clinic, public hospital)

- Commercial Director (non-profit hospital )

- Managing Director (private hospital (P KKH))

- Medical Director (non-profit hospital, public hospital)

- Nursing Service Management (non-profit hospital, private hospital)

- Quality Manager (non-profit hospital, public hospital)

- Ward Doctor (non-profit hospital, private hospital). 
Table 1. Hospitals participating in the evaluation, status 2012

\begin{tabular}{|c|c|c|c|c|}
\hline $\begin{array}{l}\text { Facility/ } \\
\text { operator }\end{array}$ & Approval & Beds & Employees & $\begin{array}{c}\text { Patients } \\
\text { (inpatients) } \\
\text { /cases per year }\end{array}$ \\
\hline $\begin{array}{l}\text { University clinic- } \\
\text { Corporation of } \\
\text { public } \\
\text { law//Federal state }\end{array}$ & Maximum care & $\begin{array}{l}3200 \text { beds/ } \\
100 \text { clinics } \\
\text { grouped in } 17 \\
\text { centres }\end{array}$ & 13.000 & Approx. 136,000 \\
\hline $\begin{array}{l}\text { Municipal hospi- } \\
\text { tal as state-run } \\
\text { enterprise /Local } \\
\text { authority }\end{array}$ & $\begin{array}{l}\text { Acute care } \\
\text { hospital with } \\
\text { specialised } \\
\text { medical services }\end{array}$ & $\begin{array}{l}960 \text { beds/ } \\
15 \text { clinics and } \\
\text { special } \\
\text { wards/ } 3 \\
\text { centres }\end{array}$ & 1800 & Approx. 35,000 \\
\hline $\begin{array}{l}\text { Denominational } \\
\text { hospital as an } \\
\text { association/ So- } \\
\text { cial welfare asso- } \\
\text { ciation }\end{array}$ & $\begin{array}{l}\text { Acute care } \\
\text { hospital with } \\
\text { basic medical } \\
\text { services }\end{array}$ & $\begin{array}{l}240 \text { beds/ } \\
5 \text { special } \\
\text { wards/ } 3 \\
\text { centres (certi- } \\
\text { fied) }\end{array}$ & 600 & Approx. 12,000 \\
\hline $\begin{array}{l}\text { Hospital as } \\
\text { GmbH [private } \\
\text { limited company]/ } \\
\text { District/Local } \\
\text { authority }\end{array}$ & $\begin{array}{l}\text { Acute care } \\
\text { hospital with } \\
\text { basic medical } \\
\text { services/ spe- } \\
\text { cialised medical } \\
\text { services and } \\
\text { other hospital } \\
\text { psychiatric care }\end{array}$ & $\begin{array}{l}4 \text { hospitals/ } \\
\text { totalling } \\
\text { approx. } 1000 \\
\text { beds }\end{array}$ & 1900 & Approx. 32,000 \\
\hline Helios-Klinikum* & $\begin{array}{l}\text { Acute care } \\
\text { hospital with } \\
\text { basic medical } \\
\text { services and } \\
\text { specialised } \\
\text { medical care }\end{array}$ & $\begin{array}{l}570 \text { beds/ } 15 \\
\text { clinics }\end{array}$ & 1000 & Approx. 24,000 \\
\hline
\end{tabular}

*The HELIOS Kliniken Group is made up of 74 own clinics, including 51 acute care hospitals and 20 rehabilitation clinics and medical care centres, status as in December 2013. HELIOS provides eservices in all areas of patient care, from the outpatient and inpatient acute medical care to rehabilitation and geriatric care.

Source: own research. 


\section{The central questions ( table 2) were developed.}

Table 2. Guideline for conducting interviews in the hospitals

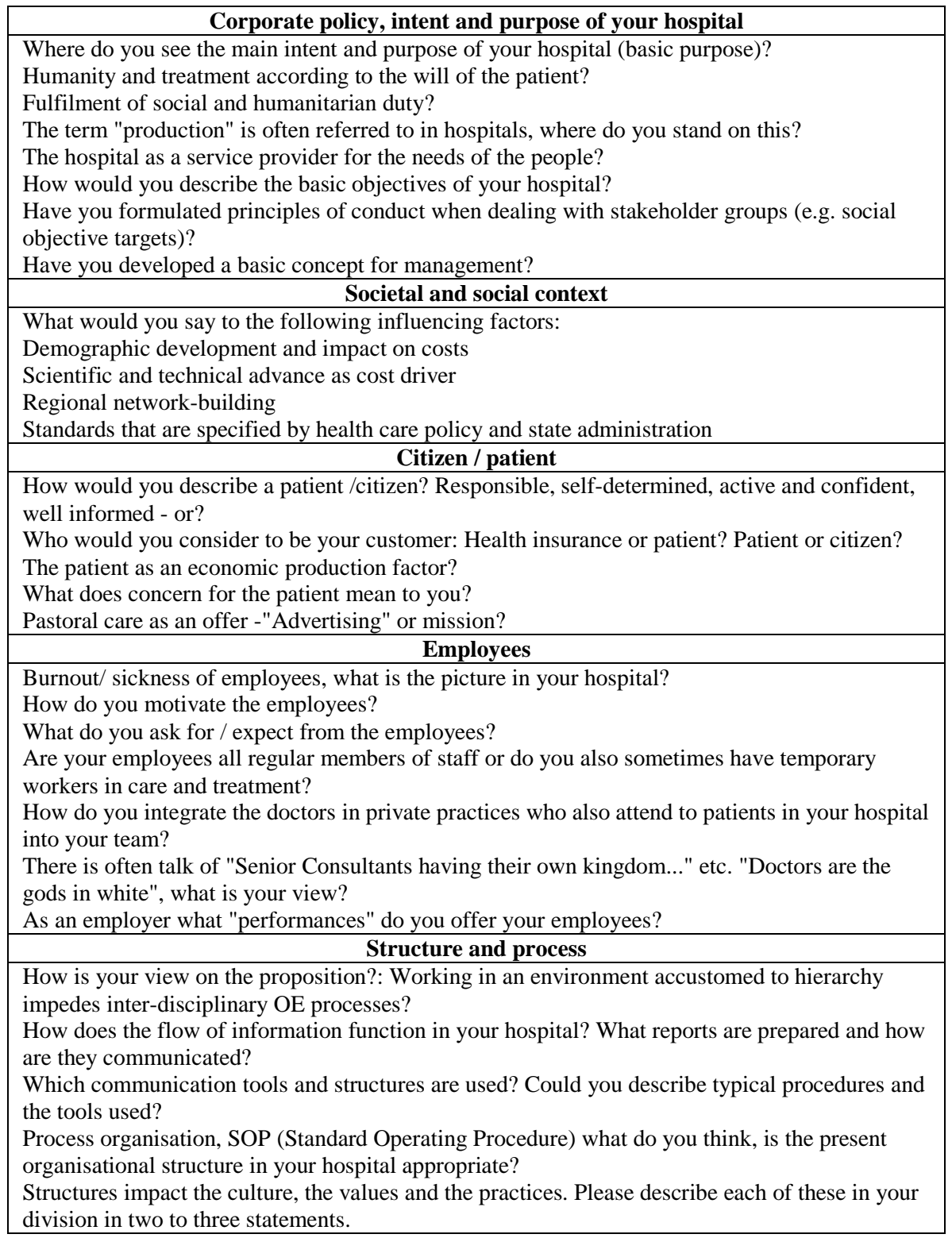




\section{Table 2 continued}

\section{Economy/ quality as area of tension}

What is your view on: Conduct and relationships of organisation members: thinking and acting in the interest of the organisation (intrapreneurs) or thinking and acting in their own interest? What has priority? Economy or quality? How are these measured at first?

What is your view on: Conduct and relationship of doctors to care/ patient? Competent, responsible, exploitation of power gap?

Can you state your strategy in a few words?

\section{Strategy (Strategic Management)}

Who is the funding body and do you know its strategy and how are you as the hospital involved in implementing the strategy?

Could you please describe how the strategic planning process works in your hospital?

How do you measure the success of the planning targets?

What are the most important key figures, indicators with which you measure the success of your hospital?

How was the mission statement developed? Who was involved in the process? How is the mission statement communicated?

In one sentence, describe how you see your hospital 10 years from now?

Are you familiar with the macroenvironmental analysis tool PEST or the Five Forces model?

Do you use these tools?

Specialisation, standardisation, segmentation, comprehensive care, integrated care, patientcentred care, what comes to mind when you hear these terms?

What do you think of network structures, how would you describe your present situation and which related developments could you imagine?

Who are your most important stakeholders? How do you involve them in your business?

What is your opinion on key figure systems, such as e.g. the Balanced Scorecard?

Are you using a similar system?

How often and with whom do you meet for so-called strategy meetings? What is the outcome of such meetings? How do you develop your strategy further?

What is more important in your view: Placing the patients at the focus or the basic economic conditions for the hospital?

Please briefly describe the cooperation with the doctors in private practice. Who is the Owner of the patient data?

How often do you follow the situation in your "rival hospitals"? Do you look at e.g. market share, patient numbers, case numbers, etc.? And do you follow the development of your "rival's" portfolio?

Are you judged by the attainment of the strategic objective targets?

Do you judge the responsible officers of the subordinate hierarchies by the strategic target attainment?

Who bears the responsibility for what in your hospital?

As how functional and success promoting would you characterise and assess your management organisation (perhaps three-person board)?

If you were to summarise the trend in the healthcare system, how would you describe it?

Which IT is used in your hospital?

What are the most important challenges for the immediate future that you must tackle as hospital management and what areas for action do you see here?

Strategic planning: Do you have a 5-year plan?

Do you have a budget on a multi-annual basis?

Please describe the planning process. 


\section{Table 2 continued}

\begin{tabular}{|l|}
\hline \multicolumn{1}{|c|}{ Operative management } \\
\hline What are your most important targets in this year? \\
\hline What kind of cost accounting do you perform? Do you already calculate using the hospital fee \\
system InEK [Institut zur Entwicklung des Entgeltsystems im Krankenhaus]? Do you already \\
use activity-based costing? \\
Do you have a breakeven analysis? Could you please describe it briefly? \\
\hline Please describe the annual planning process. Do you set cost targets in the budget? Based on \\
what? Do you negotiate these with the specialist clinics? \\
On which level is the budget employed? \\
Do you have a business plan? \\
\hline Does accounting controlling take place in your hospital? \\
How is the medical documentation performed? How would you judge the quality here? \\
Key word: revenue controlling how does that work in your hospital? \\
What are the most important operative key figures that you use to manage the hospital? \\
On which function level are these key figures employed? \\
\hline Do you have a Quality Manager? What tasks and functions does he fulfil? \\
Do you have a process handbook? \\
What is the status of the conversion to standardised treatment paths? \\
\hline How do your measure the utilisation of your infrastructure? (Equipment / operating theatres / \\
beds etc.) \\
\hline Which role does controlling play and where is it located? \\
Do your perform target-performance comparisons / deviation analyses / proposals for action / \\
assumption monitoring? \\
\hline Reducing the length of stay: How do you control this? \\
\hline Do you measure patient and also employee satisfaction? \\
\hline
\end{tabular}

Source: own research.

Proceeding from the idea that "telling stories" is a better way to record subjective perceptions, emotions and feelings than in a controlled interview, the following 10 interviewees participated in a narrative interview:

- Head of Division Corporate Development (public hospital)

- Commercial Director (non-profit hospital)

- Managing Director hospital association (public hospital) 
- Managing Director (private hospital, public hospital)

- Quality Manager (non-profit hospital, public hospital)

- Head of Human resources (public hospital)

- Controller (public hospital, non-profit hospital)

- Doctors (public hospital, non-profit hospital, private hospital)

- Nursing staff (public hospital, non-profit hospital, private hospital)

- Specialist nurse (public hospital, non-profit hospital, private hospital)

Various questions from the guideline interview were used to encourage the interviewees to talk and tell. The group discussion is closely related to the method of questioning and can be seen as a "specific form of group interview" (Lammek, 1995, p. 125); in other words as a talk under "laboratory conditions", in which several people provide information on a topic that a discussion leader defines. In this case the talks were rather of an "investigative" nature that means the focus during the discussion was on the information than content results. By using this method the author was primarily interested in recording the opinions and attitudes of the individual participants of a group, and checking whether these deviate from the group opinion (e.g. when investigating the goals of the individuals participants, the researching of the values and maxim for acting of the individuals as well as of the group as a whole) in addition to analysing how the problem solving functions in the group (e.g. in the board meeting as well as in the coffee break in the non-profit and in the public hospital).

Observation in the narrower sense is understood as collecting experience (data) in a non-communicative process using all possibilities of perception. In contrast to day-to-day observation, the scientific observation is more focused, method-controlled and inter-subjective. It typically uses tools that guarantee the self-reflection, systematics and traceability of the observation and help extend the limits of our own ability to perceive. Using observation, quantitative and also qualitative data can be produced; the latter then form the interpretative access to the observed events (Bortz \& Döring, 1995, p. 240).

The aim of the scientific observation here was mainly the direct observation of human actions, linguistic statements, non-verbal reactions (facial expression, gestures, body language) and social characteristics (clothing, symbols, habits, etc.) The focus was on recording the course and the significance of individual actions and action patterns as well as the relationship structure. No other form of data collection permits the researcher to gain such a deep insight into the day-to-day events in a social community, the manifold moral concepts and interests of the participants and their social context. All those observed were informed in advance of the scope, execution, date and content of the observation. Amongst the tools used was a 
certification process in the hospital over two days on which all hierarchy levels including nurses and doctors of the hospital were represented. This method was used in a non-profit hospital.

Further, the qualitative analysis was evaluated according to the following structure:

Table 3. Structure of analysis

\begin{tabular}{|l|l|l|}
\hline \multicolumn{3}{|c|}{$\begin{array}{c}\text { Profiles of the hospitals according to corporate policy, } \\
\text { intent and purpose/patients/ employes }\end{array}$} \\
\hline Strategies & Structure & Systems \\
\hline $\begin{array}{l}\text { Entire hospital (fund- } \\
\text { ing) }\end{array}$ & $\begin{array}{l}\text { Processes: } \\
\text { Normative orientation process } \\
\text { Strategic decision-making pro- } \\
\text { cess } \\
\text { Operative management process } \\
\text { Management business process } \\
\text { Supportive processes }\end{array}$ & $\begin{array}{l}\text { Management system } \\
\text { (including Controlling) }\end{array}$ \\
\hline Hospital & Quality Management & Financial system \\
\hline Specialist ward / clinic & Risk management & Communication system \\
\hline Normative & Organisation structure & Incentive system: \\
\hline Strategic & Staff & \\
\hline Operative & Segmentation & \\
\hline Instruments/ methods such as e.g. mission statement, Standard Operating Procedures \\
(SOPs)/ target agreements/ key figure systems
\end{tabular}

Source: own research.

The aim is to present the strategic and operative management of the hospitals and the hospital management in the actual situation of the, in order to make conclusive statements whether and how the different operator and so the formal structure affect the management and how the individual clinic operators react to these challenges.

\section{Results}

This article refrains from presenting the actual situation in detail and rather refers to the publication by Held (2014, pp. 53-105). This paper focuses on the comparison of the hospitals in the context of meeting these challenges. 


\section{Bärbel Held}

The challenges are derived from the scenario analysis (Held, 2012, pp. 99250) and outline the following:

- securing the operative profitability and long-term existence of the hospital, ensuring the required investment (result optimisation and use)

- integrated provision of services, personalised for the patient, industrialised in the service preparation (industrialisation and realisation of personalised medical care)

- management of the own service offerings (portfolio) oriented according to the customer needs (need orientation)

- organisation of the need-oriented and end-to end provision of services along the value chain (adaptable integration of the own portfolio into a complete overall portfolio)(content portfolio integration)

- integration of the own portfolio in the regional context (the right service in the right place)(regional portfolio integration),

- ensuring a high quality level of service (Quality Management).

In a hexagonal shape the individual hospitals are now divided into public hospital as a state-run institution, non-profit hospital and private hospital, and compared regarding their potentials to meet the challenges. The potentials were derived as conclusions from the actual-analysis.

\section{Public hospital}

Typical for the public hospital are:

1. No sustainable corporate profit targets

2. Very good quality in the required services provided (particularly university clinics)

3. Regional (according to politically defined regions) competition amongst hospitals (regarding patients, funding, retention of workplaces)

4. No potential (finances) to shape transformation, scientific and technical possibilities or strategic restructuring.

5. As an individual hospital no possibility to realise inter-disciplinary, personalised medical care, innovation and clinical studies (exception: university clinic). 
Figure 1. Action areas and their implementation

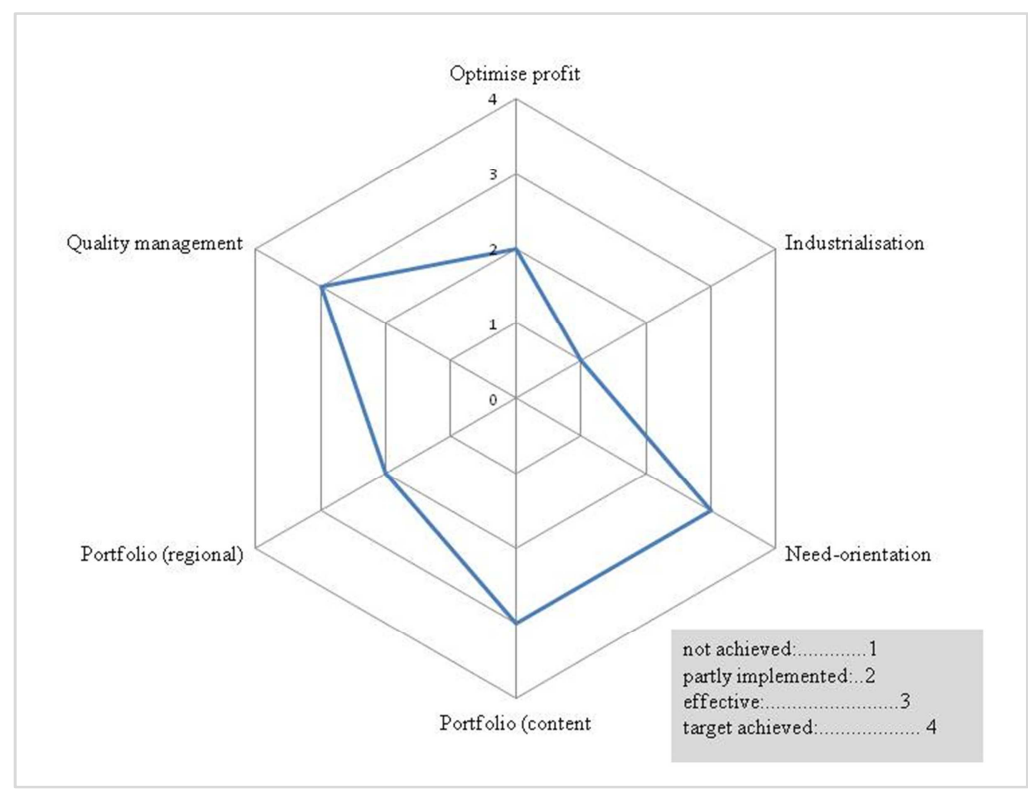

Source: own research.

The public hospitals are very good regarding the provision of services (quality). However, operative measures and the daily business, one-sided cost-saving activities (such as e.g. restructuring, outsourcing, lean management) are merely an effort to optimise the status quo. Measures to increase profitability develop substantial growth potentials by following a new strategic direction, are still missing in most public hospitals (approx. $50 \%$ of all hospitals in Germany generate losses in 2012 (www.dki.de; Krankenhausbarometer, 2012)).

Municipal hospitals are limited in their development due to the regionalising tendencies. The politically determined constituencies thus represent a management inconsistency in themselves. The financing of the restructuring can only work if sufficient funds are available, these must be earned. This means: Standardisation and industrialisation are the necessary requirements to improve the result orientation whilst maintaining stable demands on quality. Personalised medical care, standardisation and industrialisation in order to utilise the economies of scale mean being cross-regional and acting in networks and associations.

From the historical perspective, the service offerings of the public hospitals are well established. The fulfilment of the public service mission with 
a state-prescribed bed plan was and still is the main focus of hospital management. However, every public hospital acts independently, these basic conditions are now cumbersome under the partly introduced competitive conditions. Hospitals that have united to form networks, only do so in the politically determined region, to form maximum purchasing groups. Maintaining and securing workplaces is here often the primary objective. Within the region (municipality, district) instead of joining forces, the hospitals compete with one another and also with private service providers, so that they can offer their core services optimised regarding profits at a high quality level.

It is necessary that the hospitals are integrated into the holistic, patientoriented healthcare service, within a healthcare region, that is determined by the state (in cooperation with the health insurance) according to the number of insured, accessibility and other service levels.

\section{Non-profit hospital}

Typical for the non-profit hospital are:

1. Implementation potential for new strategic orientation among private hospitals

2. Regional limits regarding operator and funding

3. Very high quality in provision of services, with additional pastoral care and benefits

4. Introversive needs orientation.

The content management in the non-profit hospital is primarily geared to profit optimisation, in order to generate revenue for investments with which the need orientation is then pursued. Also here the operator (funding) is the limiting factor. The operators are likewise organised regionally. This means that the same conditions exist as with the public hospitals as a societal conflict of objectives. In contrast to the public hospitals, the profit orientation plays a greater role. As a result, networks are already being established that include a holistic healthcare service package of prevention, to diagnosis, therapy to care and rehabilitation, but also training and child care, in order to utilise the economies of scale. However, these networks or associations also do not appear as healthcare providers in a healthcare region, that means that they too do not focus on the care requirements of a region, but rather compete with other clinics for patients, for newer healthcare services etc. and are not integrated in the holistic, necessary portfolio of the healthcare region with the healthcare services they offer. 
Figure 2. Action areas and their implementation-non-profit hospitals

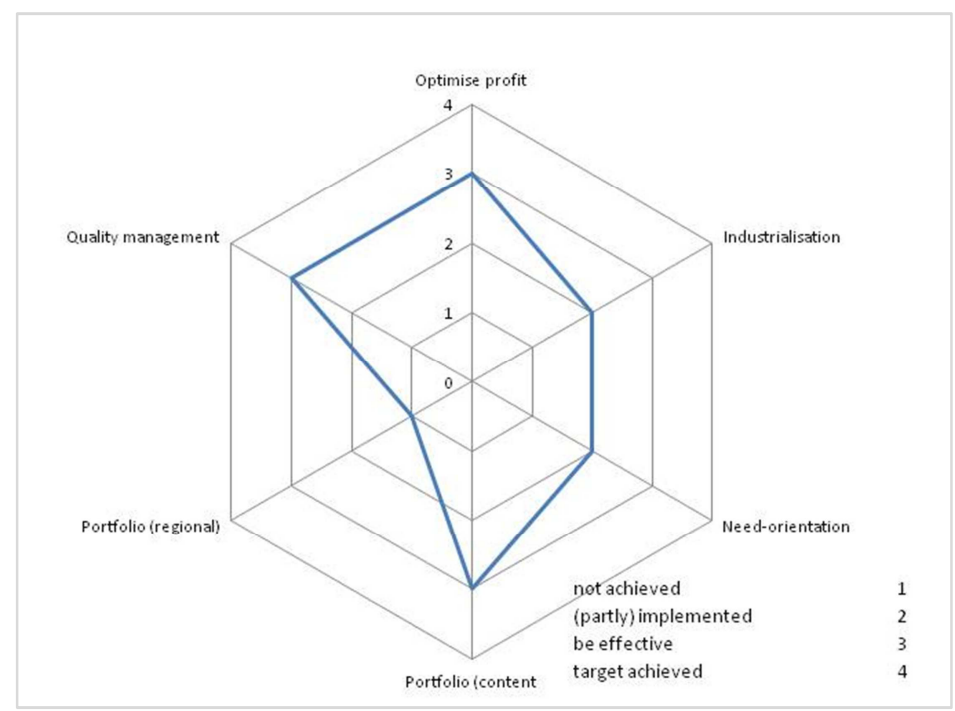

Source: own research.

\section{Private hospital}

The private hospital is:

1. Optimized within itself

2. Has sufficient potential for transformation and reorganization due to the good profit situation

3. Very high quality of healthcare service.

As a rule, it generates sufficient margins to make necessary investments and as a private provider with a good profit situation various possibilities to obtain the required funds (loans, leasing) on the financial market. However, here too the needs orientation is rather introversive, the portfolio management is geared to market and revenue aspects and is not orientated to the needs of the healthcare region. Results are measured and deviations are handled in quality management. This is necessary to be able to keep an eye on the quality level whilst optimizing profits.

The private clinics also have the potential (financial) but they do not act sustainably in the sense of the healthcare region but rather follow the profits; however, there is not yet a respective (controlled) region described and operated by a regional management. 
Figure 3. Action areas and their implementation-private hospitals

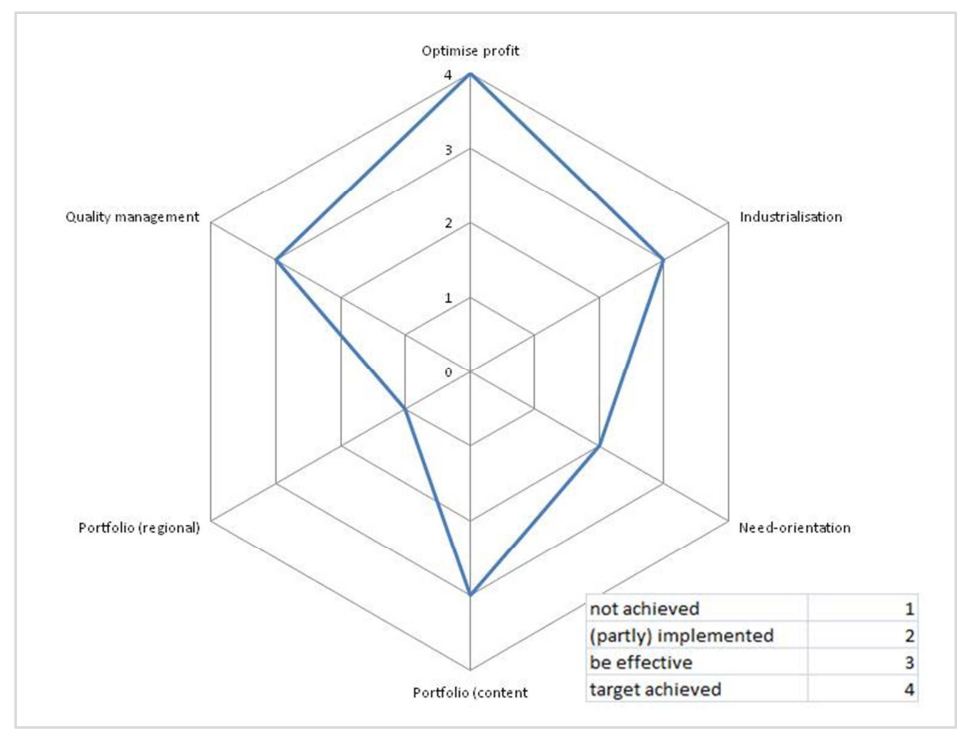

Source: own research

The clinic or the network, the limited company, the holding, the public limited company optimises itself "within itself" since it functions as a corporation. In contrast to the public hospitals, the clinics must prove their liquidity, since otherwise there is a threat of insolvency, operate profitably, since they otherwise use up expenditure without replacement, generate revenue in order to invest, plan and manage strategically, in order to safeguard the long-term existence of the hospital. This has a direct effect on the operative management, the operative targets and the shaping of the relationship between principal and agent. The managing director in the private clinic as the agent will only be able to hold his position if the targets of the principal are also achieved. This creates the pressure, which leads to targetoriented management. 


\section{Discussion of the Results - Formulating Recommendations for Action}

The results of all three types of hospital are superimposed and shown in the hexagon (figure 4).

Figure 4. Action areas and their implementation-compare

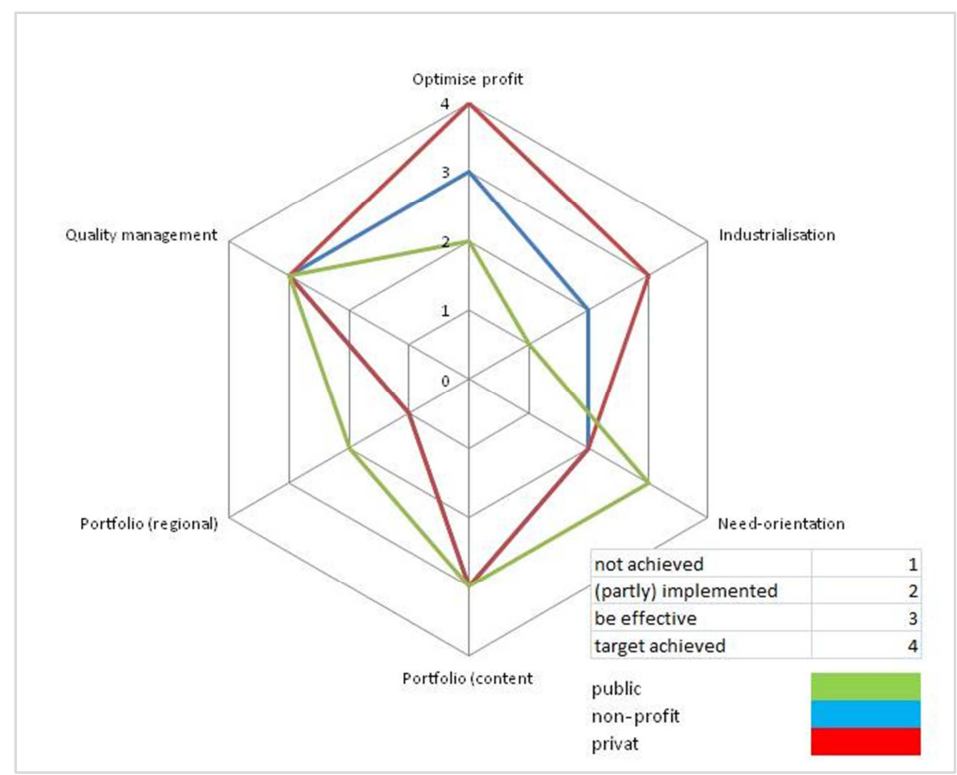

Source: own research.

It is clear to see that both the private hospitals and also the no-profit hospitals are better equipped to manage the necessary transformation process in the healthcare sector regarding their (also) economic orientation than the public hospitals. The way ahead leads to standardisation and industrialisation in order to utilise economies of scale and scope and release related learning curve effects. These principles do not need to be "introduced" but are rather shaped in the market.

The operators of the public and non-profit hospitals provide the framework, the premise and so also set the limit for the required reorganisation. It is not the management team on site that determines a respective premise of action in the hospitals, but rather the general conditions, which in turn are determined by the respective type of operator. The management in the es- 
tablishments thus depends on the respective culture and the target objectives of the operator. And this is not the necessity to be profitable, since until now there was no need to manage shortages as long as financial funds can be topped up at any time, no cost awareness, no transparency and no sustainable economic and also social (for society as a whole) action. This can be subsumed under the term: Soft Budget Constraint Syndrome (Kornai, 2009).

Kornai (2009) has analysed this phenomenon by using the example of the health care system in Hungary and he labelled it the ,soft budget constraint (SBC) syndrome“ versus "hard budgets”. He states: „The appearance of a SBC in the hospital sector is not peculiar to Hungary, or the postsocialist region. It is propensity that necessarily appears in all regions including modern, democratically governed capitalism, where state ownership, state regulations, and state financing have a necessarily great role to play. Furthermore, it reproduces itself, retreating but resurging after a time." (Kornai, 2009, p. 133)

The effects of this system guideline can be described as follows:

- The enterprises develop somewhat of a "begging mentality". They know that they have the support from the state (Held, 2014, p.75). The economy as the mayor force gets suspended (principle of scarcity).

- Soft Limitations for budget distort competition. Because of the fact that the state secures the maintenance, enterprises can act comfortable. Innovation, optimization and product development are no longer decisive for their survival (Held, 2014, p. 91).

- The support of permanently deficit enterprises cost vast sums.

- Because of a missing commitment of the enterprises, there are also profitless investments that are realised (D-M-Modell) (Dewatripont/ Maskin 1995).

All effects described by Kornai, can also be unveiled for the German health care system. Through interviews with experts and the scientific observation the same defects were detected (Held, 2014, pp.130-143). Soft Limitations for budget which lead to a suspension of the economy in the public hospitals are the fourth determinant. Results are deficiencies in the health care system that leads to entropy of the system. The term "deficiencies" does not mean there is a lack of something generally, rather it is a term we find in logistics (Jünemann, 1989, p.18). There is not the correct amount of goods or services available at the right time, at the right place and in the adequate quality. Therefore, deficiencies in the health care mean an under -coverage of the actual need of goods, deficiencies in services and economic resources, a gap in supplies of goods and services, a gap in sup- 
plies of material and equipment, deficiencies in productivity (Held, 2014, pp. 70).

The significance of an under -coverage of goods and services becomes evident if one looks at the waiting time in hospitals (http://www.dkgev.de /dkg.php/cat/62/title/Statistik), or if one takes into account that integrated, personalized supply is only available in a central-location-system. Further, there is only a more and more fragmentary supply offered in rural areas, which is not enough to offer all citizens the best possible supply with optimal prices. A planning of locations for hospitals in line with accessibility of primary care simply is not satisfactory. It is not possible to evaluate if 10 or 20 minutes to access the next hospital for the primary care is good or bad, because a benchmark is missing. It would be more needful to provide a service catalogue and guarantee its contents (e.g.: n-days to get to the next specialist, $\mathrm{n}$ hours to get to the emergency doctor, $\mathrm{n}$ minutes to get in touch with the next doctor for example via an emergency hotline, $\mathrm{n}$ minutes resource-availability) which however is not possible within the given structures.

A further significance of a deficiency is that the optimal production factor is not encouraged, e.g. input of material and manpower but rather one uses what is in place. This can be observed in hospitals. Deficiencies stimulates hoarding. Deficiencies cause an excess effort of operative administration and mislead to a neglect of perspective questions towards economic development.

Deficiencies in the health care sector lead to a delay of renewal and modernization investments (e.g. investment bottleneck) and also to a lengthening of the transition of scientific, technical renewals (e.g. therapy, medicine, innovative equipment) (Held, 2012, p.160). Results and insights of scientific studies which are directly produced within therapy are reserved for those patients who are treated in medical centres' (www.kompetenzn etze-medizin.de). Deficiencies cause extra hours and slack time simultaneously. A lot of doctors feel overburdened. One out of four works around 80 hours a week- with unforeseeable consequences for the patient. "More than 48 working hours per week, in three out of four cases of hospitalists, are increasingly becoming a risk factor for patients" (www.n24.de). Deficiencies further cause a tendency towards a self-supply of the health companies and inhibit the creation of rational relationships in terms of division of labour (Held, 2014, pp. 95-104; Phoehler, 2010). Market and competitionbased elements are introduced with the market however being unable to function with all its rules (Boehlke, et al., 2009). What are missing are real prices, market players and concrete buyers for the services offered, and to be able to choose between them respectively, thus actual competition. The 
competition that is created through the compensation system is not going into the right direction. It is not healthiness as such that is being promoted but rather sickness. One could speak of a "fight" for patients (Held, 2012, pp.147-148).

One can conclude that the survival of the current public health care sector does not depend on efficiency, innovation and effectiveness, because the financial funds are not limited (financing through debts). 19 percent of all public hospitals are bankrupt if measured and assessed by economically criteria, 51 percent make losses (www.dki.de; Krankenhausbarometer 2012), to which all university hospitals belong to (www.vdek.com). The reason for it can be found in the principle of scarcity which is the basic principle for economic behaviour but which is non- existent in this case (SBC). Alternatively, this system also means that social working potential is lying idle while needs are not met pleased. Available work (because there are unlimited needs e.g. research, gain of insights, care, education, prevention, art and culture) is present, but it is not paid for at the moment meaning that a lot of products, goods and services are excluded from the market- a fact which was already absorbed from the economy and the economic theory and was discussed under the term "shared value" as a new concept for the industry and the corporate sector (Porter \& Kramer, 2011).

As for the governmental regulation system, the regulation of the market also shows its limits. A major force of the market economy is the utilization of capital, while all other forces are subsidiary. According to Schumpeter and aimed at market realization, each innovation is based upon this fundamental drive. The utility of a product is determined by the buyer on the market and is individual and concrete at any time. Economical thinking and behaviour are the fundaments of the market economy. The public sectors' major force in the utilization of capital indirectly leads to the satisfaction of individual needs (what can be stressed, weakened or is manipulable respectively through marketing). Even less distinct and far weaker than the focus on a direct satisfaction of individual needs, there is the possibility of the public sector to focus on societal needs (e.g. sustainability, health care etc.). Although societal responsibility is accepted as a strong image-factor for private enterprises, it is not a major force as such compared to the efficient utilization of capital. The extreme value of the corporate sector, being based on the maximization of the realization of capital, eventually is the product of limited personal needs (market saturation), limited availability of resources which allows the production for market-adequate prices. Strive for efficiency leads to a progressive edging of people aside from the value creation process (not because of reasons of rationality). 
Each hospital requires the respective "freedom" to shape the integrative portfolio management to manage the relevant areas in planning (e.g. medical procedures, resources, products, business areas) under the aspects of risk, growth and revenue. The market economy is the only way to drive the efficiencies in the directly efficient design of the provision of healthcare services. This means that the establishments that were hitherto state-run must be privatised with the related consequences, the risk of insolvency. Management will act accordingly only when the hospitals have to behave under the market terms.

The next figure shows that there is space for a future healthcare service system that acts on the market without planned economic guidelines, in which each individual healthcare provider can participate, according to the quality specifications of the state regulatory body.

Figure 5. Healthcare region and hospital care offering

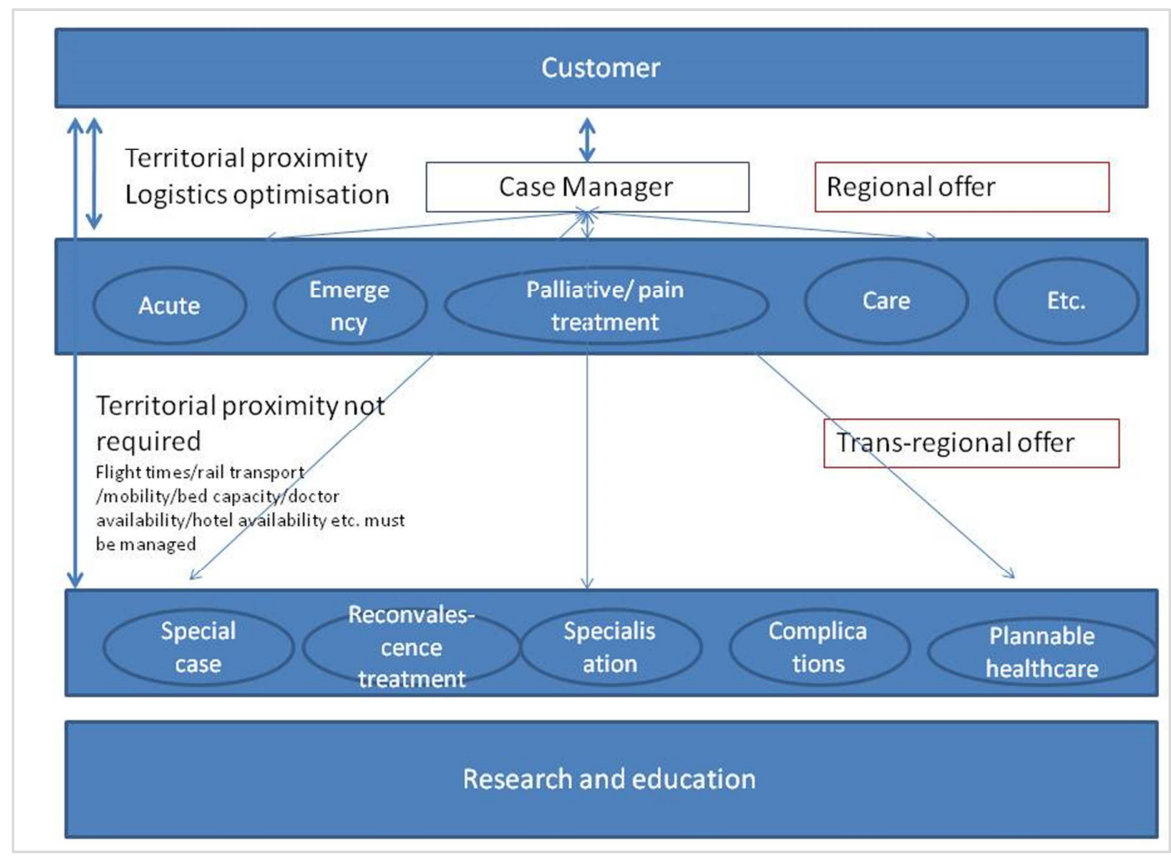

Source: own research. 


\section{Bärbel Held}

Market economy is not the most suitable system when it comes to shaping society. This applies especially to the healthcare system as a whole. The conditions required to ensure that the healthcare system to be created is sustainable, would therefore be for the state to determine the healthcare regions, but not according to electoral calculation or territorial aspects but rather according to the number of patients, age of the patients, mobility options (infrastructure, such as motorway, railway, airport, etc.) and then advertise for bids from the healthcare service providers. The healthcare system will be organised as a mixture between market and hierarchy. Public Governance appears in the form of a state regulatory body which possesses as a hierarchy and so as a positional authority over sanctions and rewards and which checks the provision of the services, as well as defines rules for the healthcare market, such as e.g. defining care corridors for the patients.

The Institute for Quality and Efficiency in the Healthcare Systems will be introduced here as an example. Since its founding in 2004, the legislative principles and tasks of the institute have been anchored in the Sozialgesetzbuch V [German social security stature book] and have been amended and expanded in further healthcare reforms. The only initiators are the Gemeinsame Bundesausschuss (G-BA) [German Joint Government Committee] and the [German] Ministry of Health. The tasks of the independent scientific institute are to investigate benefit and damage of medical measures for patients, to provide information on the advantages and disadvantages of therapies and diagnosis methods and prepare expert reports on, for example: medicines, non-medicinal treatment methods (e.g. surgery methods), procedures of diagnosis and screening as well as treatment and care guidelines and Disease Management Programs.

Alongside the monitoring of quality for the provision of healthcare services, the service and profitability for the citizen/patient must also be monitored and regulated, whereby it is necessary to define appropriate service levels for the citizen / patient and also define quality standards and monitor their observance by the healthcare providers and where necessary impose sanctions (e.g. revoke the business operating license).

The supervisory board of the healthcare region, which is for example made up of health insurance representatives, local and municipal representatives etc. is personalised and also bears personalised responsibility. The supervisory board has the possibility to advertise for bids to provide a healthcare service in a healthcare region and license various healthcare providers that now compete for Quality and Prices. In turn, these providers can merge to form large networks that act (efficiently) also outside a healthcare region and so also cross-regionally. The citizen is committed per 
contract to a healthcare provider for a defined period of time (e.g. two years). He has the possibility to freely select a doctor after comparing offers (price and quality) and with a personal Case Manage at his side to support and guide him.

Each hospital must then find its place within the advertised healthcare region with an integrative portfolio management according to various strategic reference points and management perspectives. The management of the hospital from an isolation observation horizon raises the risk of a difficult business situation. Today the following is regulated by the state; how many beds the hospital may have, whether it is part of the basic-regular or the maximum healthcare system, the revenues for healthcare services rendered are regulated by the state and the actual customer does not appear as a customer, he is even completely unaware of many of the prices for the care and services provided, the health insurance ifs the actual negotiation partner for the hospitals. They negotiate the cases and the prices. Following the new model, the hospitals themselves decide, depending on the core competence, which healthcare services they provide in the integrated healthcare system and with whom they cooperate, which financial model they choose etc. The required healthcare, service and quality standards are defined and there is a direct customer, the patient, who pays for the services. (The prerequisite would be a health insurance that covers a defined healthcare service corridor but does not constrict the patient as the customer). This requires, alongside the integrative portfolio management, innovative service management to develop new business areas and finally effective management with interdisciplinary supply chains and also integrated supply architecture. This in turn requires standardisation and industrialisation in order to provide the patient with personalised medical care that is affordable, highly modern and permits the healthcare provider to generate the required profits. The prerequisite here would be to include the entire resource consumption into the price of the healthcare services, and not, as is the case today, only to calculate the current expenses. Determining the location of the hospital, in other words, the question "Where do I want to go" can only be answered if the strategy, the way there, is geared to business.

It is therefore important that the hospital management rises to the challenge of value innovation as a growth option using newly defined benefits from the point of view of different patient groups and so develops new areas for growth for itself. The prerequisite here would be that the incentive structure in the healthcare system were turned around and thus connected to a radical, new definition of the business purpose. Only then will new growth areas be opened up for the hospital. Still today growth in the hospi- 
tals means: Equipping hospitals, securing healthcare assignments and bed numbers, exploiting bed capacities and gaining patients that require the most expensive operations possible. A reversal of the incentive structure would lead to a change in the purpose definition of the hospitals and from then on the "Value of Health" and not longer the "Value of Disease" would be at the centre of the entrepreneurial activities.

\section{Conclusions}

The analysis has shown that the private hospital groups are the only players that have the necessary innovation resources and also the necessary market pressure to be innovative. But, the negative consequences of the dominance of these private corporations have been described. Government hospitals are arrested in their structures. An outdated planning model, the soft budget constraint, the corporatist system of organization and lack of entrepreneurship are the main causes of the defects in public hospitals. All described elements tend to cause an erosion of the corporatist, organized health care sector on its way to classical bankruptcy and towards a private system within the scope of service provision while preserving the model of a solidary health insurance financing. Here, the state keeps on disappearing from investment financing of the hospitals. The employer's contribution regarding health insurance, locked up through the political decision- makers, allocates the rising costs to the insurant even greater.

Simultaneously, the growing offer of direct and chargeable health care services is only partly paid by the insurance. Step by step, the patient becomes the financier of the health care system subsequently leading to a point where he is a player and customer in the health care market, thus puts pressure on the system himself. The patient becomes the subject rather than being the object which means that he is put in the position where he is able to make decisions rather than being the object of other stakeholders' actions. More and more active patients demand for:

1. Transparency of information towards the players (information about doctors in the internet and rankings of hospitals) and focus on his needs.

2. Transparency of performance/ quality ( therapy $\rightarrow$ cost/ benefit evaluation)

3. Cost- and efficiency transparency therapy $\rightarrow>$ benefit/ cost evaluation).

It becomes evident that working competition requires the same basic premises for all players. Therefore, they have to be set and must be applied nationally (antitrust law). 
On the contrary, a supply that fits the needs must be oriented on the differing social and local/regional needs, thus requires a decentralized management (Böhm, 2008, p.74). The central question, subsequently, is how the three principles (1) an efficient and market-oriented organized health care sector, (2) the social principle of balance of the public services in the health care sector (3) and the local/ regional reachability of the health care services are organized and linked with each other. General problem solving will only occur if management in the health care sector orientates itself on the principles of "hard budgets". „The entry of non-state companies and private capital must be combined with reinforcement of government regulation and control." (Kornai \& Eggleston, 2001, Cap.7) "The way must be opened for the entry of non-state forms of ownership, among other reasons because there are improved changes of hardening the budget constraint on private business. It is desirable to have supply-side competition in the hospital sector." (Kornai, 2009, p.133) A first problem- solving scenario for the German regional health care supply was worked out (Held, 2014), which has the citizen being a shareholder as its central point. Here, the market in the form of a privately organized health care service provision is the mean (coordination tool) and a union or a stock company stands as the medium. The following basic principles determine this scenario.

- Health is not a common good; supply of health care is a service.

- The patient transforms from being the object into being the subject (transparency/ service/ quality/ costs).

- Replacement of SBC (soft budget constraints) of the central planning with „hard budgets“.

- Industrialised service structures (Customer Care, Delivery, Resource Management) (Held, 2012, pp. 234-239).

The concrete forming of this model like for example the forming of public governance, civil governance, the relations of distribution and - mechanisms need further evaluation, research and discussion.

\section{References}

Böhlke, N., Gerlinger, T., Mosebach, K. et al. (2009). Privatisierung von Krankenhäusern. Hamburg: VSA Verlag.

Böhm, K. (2008). Politische Steuerung des Gesundheitswesens Die Rolle von Korporatismus und Wettbewerb im Krankenhaussektor. Frankfurt-Main: Diskussionspapier.

Bortz, J.\& Döring , N. (2006). Forschungsmethoden und Evaluation für Humanund Sozialwissenschaftler. Heidelberg: Springer-Lehrbuch. 


\section{8}

Dewatripont, M., \& Maskin, E. (1995). Credit and Efficiency in Centralized and Decentralized Economies, Review of Economic Studies, 62.

DKG (2012). Deutsche Krankenhausgesellschaft. Retrieved from: http://www.dk gev.de/dkg.php/cat/62/title/Statistik. (30.12.2012).

DKI (2012). Deutsches Krankenhausinstitut. Retrieved from: http://www.dki.de. (30.12.2012).

Held, B. (2012). Nachhaltiges Gesundheitswesen in Deutschland, Teil 1: Trends im Gesundheitswesen und deren Auswirkungen auf die Struktur der Gesundheitsversorgung unter Anwendung der Szenarioanalyse, In: B. Held (Ed.). New Public Management. Bd. 2., Stuttgart.

Held, B. (2014). Gesundheit unternehmen! Unternehmen Gesundheit? Civil Private Partnership für eine bessere Gesundheitsversorgung. In: B. Held (Ed.). New Public Management. Bd. 4. Stuttgart.

Jünemann, R.(1989). Materialfluß und Logistik. Systemtechnische Grundlagen mit Praxisbeispielen, Berlin-Heidelberg: Springer Verlag.

Kornai, J. \& Eggleston, K. (2001). Welfare, choice and solidarity in transition: Reforming the health sector in Eastern Europe. Cambridge: Cambridge University Press.

Kornai, J. (2009). The soft budget constraint syndrome in the hospital sector. International Journal of Health Care Finance and Economics, 9

Lamnek, S. (1995). Qualitative Sozialforschung. Band 2. Weinheim: Beltz, Psychologie Verlag Union.

Luhmann, N. (1971). Politische Planung, Aufsätze zur Soziologie von Politik und Verwaltung. Opladen: Westdeutscher Verlag.

Luhmann, N. (1984). Soziale Systeme Grundlegung einer allgemeinen Theorie. Frankfurt am Main: Suhrkamp.

MB (2013). Marburger Bund. Retrieved from: http://www.n24.de. (11.03.2013).

Pföhler, M. (2010). Klinische Behandlungspfade: Theoretisch und empirisch gestützte Erfolgsfaktoren für ressourcenorientierte Implementierung in Krankenhäusern, in: Schriften zur öffentlichen Verwaltung und öffentlichen Wirtschaft. Berlin: Berliner Wissenschaftsverlag.

Porter, M. \& Kramer, M.R. (2011). Creating Shared Value, Harvard Business Review, 89(1/2). 